\title{
Genetic differences based on AFLP markers in the mosquito species Anopheles darlingi collected in versus near houses in the region of Porto Velho, RO, Brazil
}

\author{
L.M. Santos ${ }^{1}$, R.A. Gama ${ }^{2}$, A.E. Eiras ${ }^{1}$ and C.G. Fonseca ${ }^{1}$ \\ ${ }^{1}$ Departamento de Biologia Geral, Instituto de Ciências Biológicas, \\ Universidade Federal de Minas Gerais, Belo Horizonte, MG, Brasil \\ ${ }^{2}$ Departamento de Microbiologia e Parasitologia, Centro de Biociências, \\ Universidade Federal do Rio Grande do Norte, Natal, RN, Brasil \\ Corresponding author: C.G. Fonseca \\ E-mail: cleusa.fonseca@gmail.com
}

Genet. Mol. Res. 9 (4): 2254-2262 (2010)

Received August 2, 2010

Accepted September 3, 2010

Published November 16, 2010

DOI 10.4238/vol9-4gmr994

\begin{abstract}
Anopheles darlingi is the most important malaria vector in Central and South America. After a dramatic reduction of malaria cases in the whole Brazilian territory, with the lowest abundance being attained by 1970, the disease resurged in the Amazon region, where it is now a great public health concern. Consequently, better knowledge about vector species became urgent. We examined the genetic diversity and population structure of $A$. darlingi, sampled in four localities in the State of Rondônia, Brazil, using 139 amplified fragment length polymorphism marker loci. In each locality, samples were collected in two environments: a peri-domicile one (in the balconies of houses) and an extra-domicile environment (about $15 \mathrm{~m}$ from the house). Estimates of expected heterozygosity, Shannon diversity index and percentage of polymorphic loci showed medium to high values, with the samples from the areas closer to Porto Velho exhibiting the smallest values. There was evidence of small population differences, evaluated by $\mathrm{F}_{\mathrm{st}}$, genetic distance and analysis of molecular variance. Comparison between peri- and extra-domicile samples showed greater values of
\end{abstract}


$\mathrm{F}_{\text {st }}$ and genetic distance than between pairs of localities, indicating influence of environmental conditions on the genetics of populations.

Key words: Malaria vector; Anopheles darlingi; AFLP; Amazon region; Genetic variability; Population differences

\section{INTRODUCTION}

Anopheles darlingi is the most important malaria vector and the most anthropophilic and endophagous species in Central and South America (Conn et al., 2001), especially in the Amazon region, because of its high degree of anthropophilism and susceptibility to infection with different kinds of Plasmodium (Magris et al., 2007). The species has a discontinuous distribution in South America, from Colombia to northeastern Argentina (Manguin et al., 1999).

Anopheles darlingi exhibits great variation in its hematophagic activity (Gama et al., 2009), which may be a consequence of multiple factors, such as the use of insecticides (Conn et al., 2006), differences in temperature, amount of rainfall, genetic variability, and habits of local inhabitants (Charlwood and Hayes, 1978; Rozendaal, 1990).

Differences in body size (Charlwood, 1996), behavior, isoenzymes, and chromosomal patterns, found in different populations of the species, have created some uncertainty about its taxonomy (Rosa-Freitas et al., 1992), but biochemical and molecular studies support the hypothesis that $A$. darlingi is a single species (Rosa-Freitas et al., 1992; Manguin et al., 1999).

In the recent history of malaria in the Amazon region, a drastic reduction in the number of cases was achieved by a campaign started in the 1940s, which included the diagnosis and treatment of ill people, and the control of transmission. The last program was mainly based on the elimination of mosquitoes, spraying insecticides in the inner walls of houses. In 1945, DDT was introduced in the country and was used inside the houses. The success of the transmission control was explained by the endophily and endophagy of $A$. darlingi. Now there is evidence of a change in this pattern: the transmission occurs mainly in the peri-domicile. For instance, Gil et al. (2007) reported the risk of malaria infection indoors and outdoors as being 2 and 10/infecting bites per year per inhabitant, respectively.

As a result of the campaign, the number of cases was drastically reduced, and by 1970 the lowest recorded levels of malaria cases were achieved in the whole country. However, in the following years, the number of malaria cases began to rise, particularly in the Amazon region, where it attained very high levels. In the last decade, the number of cases in the Amazon represented more than $99 \%$ of the Brazilian total number. An examination of the number of cases by year from 1990 to 2009 indicates 2005 as a peak year, with 606,067 cases in the Amazon region. The State of Rondônia has had not only a high number of cases, but also one of the highest proportions as compared to the population number. In 2009, the number of confirmed cases of the disease was 41,362 , corresponding to $2.91 \%$ of the state's population (Ministério da Saúde, 2009).

Gil et al. (2007) reported high A. darlingi population density in a neighborhood of Porto Velho, a high incidence of malaria cases occurring at the peak of rainfall and sporadic peaks during the dry season. The region is marked by environmental changes caused by man, with houses built without the necessary precautions to avoid artificial breeding sites for mosquitoes. These facts contribute to the maintenance of high levels of malaria incidence in the region (Gil et al., 2007).

A series of studies in the last decades were conducted in order to clarify the genetic vari- 
ability and structure in populations of $A$. darlingi in Central and South America (Rosa-Freitas et al., 1992; Mendes-dos-Santos et al., 1999; Manguin et al., 1999; Malafronte et al., 1999; Santos et al., 1999; Conn et al., 2006; Scarpassa and Conn, 2007; Mirabello et al., 2008). In general, the studies revealed medium to high levels of genetic variability and low or moderate population structure.

The aims of the present study were to estimate genetic variability and population differences in the population of $A$. darlingi in the region of Porto Velho (RO), and to identify possible differences between samples collected in the peri-domicile and extra-domicile environments at four different sites.

\section{MATERIAL AND METHODS}

\section{Mosquito collection}

Mosquitoes were collected in December 2005 from four sites in the State of Rondônia,

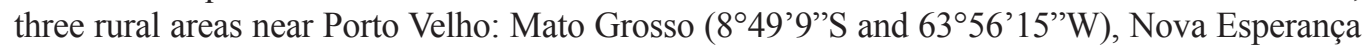

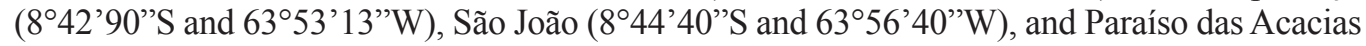
( $8^{\circ} 48^{\prime} 35^{\prime \prime} \mathrm{S}$ and $\left.63^{\circ} 41^{\prime} 44^{\prime \prime} \mathrm{W}\right)$. The first three are rural areas close to Porto Velho, the capital of the State of Rondônia, and the last one is a small village in Candeias do Jamari city, located 20 $\mathrm{km}$ from Porto Velho. Candeias do Jamari had, in 2008, one of the highest incidences of malaria in Brazil: 4385 cases in 17,547 inhabitants, or approximately 25\% (SIVEP-malária; FNS, 2010). In the same year, Porto Velho had the highest number of cases in Brazil, 22,271 or 7.2\% of the total of cases in the country (SIVEP-malária; FNS, 2010). In all these places, the presence of Anopheles, with the prevalence of $A$. darlingi, was reported (Gama et al., 2009).

As can be seen in Figure 1, São João is on the left side of the Madeira River, while Porto Velho is on the right bank. Nova Esperança and Mato Grosso are situated north and south of Porto Velho. Finally, on the right side of the square in Figure 1, we can see Candeias do Jamari.

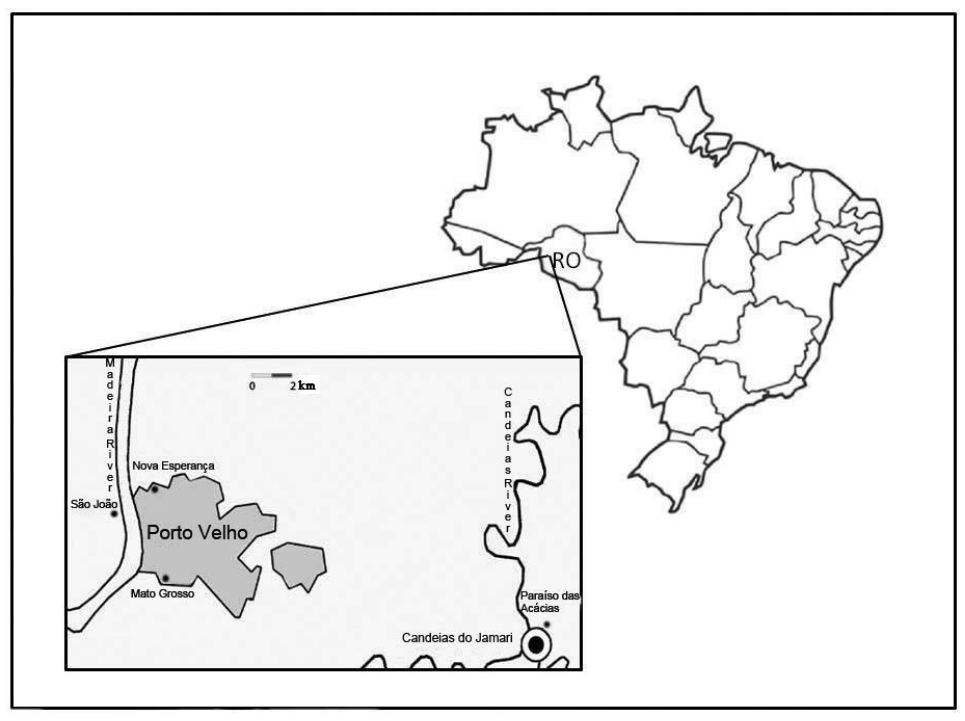

Figure 1. Mosquito collection points near Porto Velho, RO, Brazil. 
Captures were made by human landing, performed according to Gama et al. (2009) by trained technicians, at dusk (from 18:00 to 21:00 h) in the peri-domicile environment (on the balcony of houses) and extra-domicile environment (about $15 \mathrm{~m}$ from the house), in each of the sites previously mentioned, totaling eight mosquito samples, corresponding to four collection points, each one with two environments. The specimens were identified in the entomology laboratory of LACEN-RO according to Consoli and Oliveira (1994) and Forattini, (2002). The specimens identified were maintained in $95 \%$ ethanol for preservation and subsequent DNA extraction.

\section{DNA extraction}

DNA was extracted from mosquitoes' head, thorax and legs using the DNeasy ${ }^{\mathbb{B}}$ Tissue kit, following the DNeasy Tissue Handbook (Qiagen, CA, USA).

\section{AFLP reactions}

Amplified fragment length polymorphism (AFLP) assays were performed using a

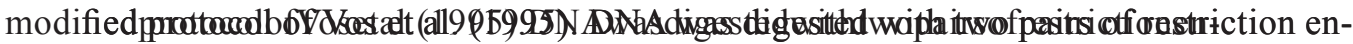
donucleases, EcoRI/MseI, and ApaI/TaqI (Janssen et al., 1996). Adaptors (Table 1) were ligated by T4-DNA ligase on both ends of genomic fragments, and a preamplification was performed with AFLP primers for EcoRI/MseI adaptors (EcoRI+G/Mse I+T) and ApaI/ Taq I adaptors $(A p a \mathrm{I}+\mathrm{G} / T a q \mathrm{I}+\mathrm{G})$. Preamplification polymerase chain reaction (PCR) was conducted for 20 cycles for $60 \mathrm{~s}$ at $94^{\circ} \mathrm{C}, 60 \mathrm{~s}$ at $56^{\circ} \mathrm{C}$, and $1 \mathrm{~min}$ at $72^{\circ} \mathrm{C}$; the primers for preamplification had one selective nucleotide. Subsequently, a selective amplification was performed using two primer combinations with three selective nucleotides for each enzyme pair $(E c o \mathrm{RI}+\mathrm{GCA} / M s e \mathrm{I}+\mathrm{TAC}, E c o \mathrm{RI}+\mathrm{GCA} / M s e \mathrm{I}+\mathrm{TTG}$ and $A p a \mathrm{I}+\mathrm{GCA} /$ Taq $\mathrm{I}+\mathrm{GAC}, A p a \mathrm{I}+\mathrm{GAC} / \operatorname{Taq} \mathrm{I}+\mathrm{GCA})$. The conditions of selective amplification PCR were: 1 cycle at $94^{\circ} \mathrm{C}$ for $30 \mathrm{~s}, 65^{\circ} \mathrm{C}$ for $30 \mathrm{~s}$, and $72^{\circ} \mathrm{C}$ for $1 \mathrm{~min} ; 11$ cycles at $94^{\circ} \mathrm{C}$ for $30 \mathrm{~s}$, $65^{\circ} \mathrm{C}$ for $30 \mathrm{~s}$, and $72^{\circ} \mathrm{C}$ for $1 \mathrm{~min}$, with decreasing temperature in the second step by $0.7^{\circ} \mathrm{C}$ for each cycle, and 23 cycles at $94^{\circ} \mathrm{C}$ for $30 \mathrm{~s}, 56^{\circ} \mathrm{C}$ for $30 \mathrm{~s}$, and $72^{\circ} \mathrm{C}$ for $1 \mathrm{~min}$, followed by 1 cycle at $72^{\circ} \mathrm{C}$ for $15 \mathrm{~min}$. Amplification products were then separated on a $6 \%$ denaturing polyacrylamide gel, and the fragments were detected by silver staining and scored as discrete character states (presence or absence).

\begin{tabular}{llll}
\multicolumn{2}{l}{ Table 1. Adaptors and primers for amplified fragment length polymorphism reactions. } \\
\hline & & Adaptors & Primers \\
\hline EcoRI/MseI & EcoRI & 5'-CTCGTAGACTGCGTACC-3' & 5'-GACTGCGTACCAATTC-3' \\
& 5seI & 5'-AATTGGACGCAGTCTAC-3' & \\
& 5'-GACGATGAGTCCTGAG-3' & 5'-GATGAGTCCTGAGTAA-3' \\
ApaI/TaqI & 3paI & 5'-TCGTAGGACTCAT-5' & \\
& 5'-TGAACGCAGCGTACAGGCC-3' & 5'-GACTGCGTACAGGCCC-3' \\
& 5'-GACGATGAGTCCTGAC-3' & 5'-CGATGAGTCCTGACCGA-3' \\
& 5'-CGGTCAGGACTCAT-3' & \\
\hline
\end{tabular}

\section{Data analysis}

Genetic variation of the $A$. darlingi population was studied by the calculation 
of expected heterozygosity $\left(\mathrm{H}_{\mathrm{e}}\right)$, the percentage of polymorphic loci (\%PL), molecular analysis of variance (AMOVA), Shannon's information index (Lewontin, 1972), Nei's genetic identity and distance (Magris et al., 2007), migration rates and F-statistics $\left(\mathrm{F}_{\mathrm{st}}\right)$.

Estimation of $\mathrm{H}_{\mathrm{e}}$, performed according to Lynch and Milligan (1994), and the \% $\%$ were evaluated using the GENALEX software, version 6 (Peakall and Smouse, 2006). AMOVA was performed by the procedure of Excoffier et al. (1992) to quantify the proportion of the total genetic variance that is associated with differences between populations and the proportion of genetic variance that is attributable to individual differences within populations, also using the GENALEX software, version 6 (Peakall and Smouse, 2006).

Nei's gene diversity, Shannon's information index, and Nei's genetic identity and genetic distance were calculated with the Popgene software, version 1.31 (Yeh et al., 1999). $\mathrm{F}_{\text {st }}$ statistics were estimated using the Arlequin software, version 3.0 (Excoffier et al., 2005). Multilocus similarities among individuals were assessed using distance matrices. These matrices were then subjected to principal coordinate analysis using GENALEX, based on an algorithm published by Orlocci (1978).

\section{RESULTS}

The combination of two pairs of primers and two pairs of restriction enzymes revealed 139 polymorphic loci. The total sample included 422 individuals, 122 from the locality of São João, 155 from Candeias do Jamari, 81 from Mato Grosso, and 64 from Nova Esperança. In order to better understand the distribution of genetic diversity, two approaches were adopted in the data analysis: to group the data according to the four locations and to consider, in each location, the peri-domicile and extra-domicile environments.

\section{Genetic diversity}

Different measures of genetic diversity estimated with AFLP markers, considering the four localities, are seen in Table 2. The $\mathrm{H}_{\mathrm{e}}$ values across the four samples varied between 0.285 (Mato Grosso) and 0.392 (São João). Shannon's information index varied between 0.416 (Mato Grosso) and 0.572 (São João), and the \%PL ranged from $69.06 \%$ in Mato Grosso to $94.96 \%$ in São João.

\begin{tabular}{lcccc}
\multicolumn{4}{l}{ Table 2. Genetic diversity in the population of Anopheles darlingi in four areas in the State of Rondônia. } \\
\hline & São João & Candeias do Jamari & Mato Grosso & Nova Esperança \\
\hline Sample size & 122 & 155 & 81 & 64 \\
$\mathrm{H}_{\mathrm{e}}$ & $0.392(0.009)$ & $0.354(0.013)$ & $0.285(0.017)$ & $0.330(0.015)$ \\
$\mathrm{I}$ & $0.572(0.012)$ & $0.517(0.018)$ & $0.416(0.024)$ & $0.479(0.022)$ \\
\%PL & 94.96 & 86.33 & 69.06 & 78.42 \\
\hline
\end{tabular}

$\mathrm{H}_{\mathrm{e}}=$ expected heterozygosity; $\mathrm{I}=$ Shannon's information index; \%PL = percentage of polymorphic loci.

The results of the peri-domicile and extra-domicile samples within each site are shown in Table 3. The three measures of intra-population genetic diversity have slightly higher values in the peri-domicile than in the extra-domicile, and the differences between localities show the same pattern as seen in Table 2 . 
Table 3. Genetic diversity in the population of Anopheles darlingi in four areas in the State of Rondônia, each one with two environments.

\begin{tabular}{|c|c|c|}
\hline & Peri-domicile & Extra-domicile \\
\hline \multicolumn{3}{|l|}{ São João } \\
\hline Sample size & 61 & 61 \\
\hline $\mathrm{H}_{\mathrm{e}}$ & $0.391(0.010)$ & $0.355(0.012)$ \\
\hline$I^{\circ}$ & $0.568(0.014)$ & $0.521(0.017)$ \\
\hline$\% \mathrm{PL}$ & 92.81 & 88.49 \\
\hline \multicolumn{3}{|c|}{ Candeias do Jamari } \\
\hline Sample size & 77 & 78 \\
\hline $\mathrm{H}_{\mathrm{e}}$ & $0.339(0.014)$ & $0.325(0.014)$ \\
\hline$I^{e}$ & $0.493(0.020)$ & $0.477(0.020)$ \\
\hline$\% \mathrm{PL}$ & 81.29 & 80.58 \\
\hline \multicolumn{3}{|l|}{ Mato Grosso } \\
\hline Sample size & 40 & 41 \\
\hline $\mathrm{H}_{\mathrm{c}}$ & $0.287(0.017)$ & $0.280(0.017)$ \\
\hline I & $0.417(0.024)$ & $0.410(0.024)$ \\
\hline$\% \mathrm{PL}$ & 69.06 & 68.35 \\
\hline \multicolumn{3}{|c|}{ Nova Esperança } \\
\hline Sample size & 32 & 32 \\
\hline $\mathrm{H}_{\mathrm{e}}$ & $0.308(0.015)$ & $0.294(0.016)$ \\
\hline $\mathrm{I}^{\mathrm{e}}$ & $0.453(0.022)$ & $0.428(0.024)$ \\
\hline$\% \mathrm{PL}$ & 71.22 & 76.98 \\
\hline
\end{tabular}

$\mathrm{H}_{\mathrm{e}}=$ expected heterozygosity $=2 * \mathrm{p} * \mathrm{q} . \mathrm{I}=$ Shannon's information index $=-1 *(\mathrm{p} * \operatorname{Ln}(\mathrm{p})+\mathrm{q} * \operatorname{Ln}(\mathrm{q}))$. In each case, the values of $\mathrm{H}_{\mathrm{e}}$ and I are means of all 139 loci, with their standard errors.

\section{Population structure}

Analysis of data from the four populations are shown in Figure 2, with $7 \%$ of the variance being explained by differences between groups, and the remaining $93 \%$, by withinpopulation variation. The pairwise $\mathrm{F}_{\mathrm{st}}$ estimates were significant $(\mathrm{P}<0.05)$, but small, with values ranging from 0.008 to 0.014 (Table 4).

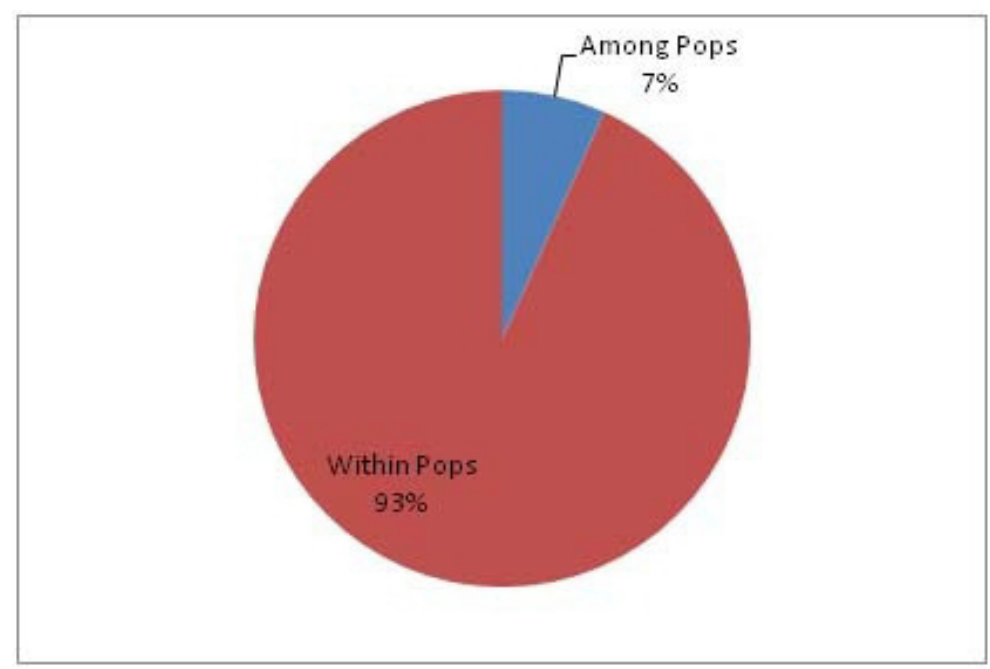

Figure 2. Results of analysis of molecular variance (AMOVA) of data from the population of Anopheles darlingi in four localities in the region of Porto Velho, State of Rondônia. Pops = populations. 
Table 4. $\mathrm{F}_{\text {st }}$ values (under diagonal) for Anopheles darlingi mosquitoes collected in the three localities in Porto Velho (RO) and Candeias do Jamari (RO), with significance levels above diagonal.

\begin{tabular}{lcccc}
\hline & 1 & 2 & 3 & 4 \\
\hline 1 & 0.000 & 0.050 & 0.050 & 0.050 \\
2 & 0.008 & 0.000 & 0.050 & 0.050 \\
3 & 0.011 & 0.010 & 0.000 & 0.050 \\
4 & 0.013 & 0.011 & 0.014 & 0.000 \\
\hline
\end{tabular}

1 = São João, 2 = Candeias do Jamari, 3 = Mato Grosso, 4 = Nova Esperança.

The estimates of genetic distance (Table 5), all significant at $\mathrm{P}<0.05$, varied from 0.042 , between the localities of São João and Candeias do Jamari, to 0.142 between the localities of Mato Grosso and Nova Esperança. Similar results were found for peri-domicile and extra-domicile comparisons for each site, with $\mathrm{F}_{\text {st }}$ values ranging from 0.013 to 0.031 (Table 6) in the localities of Candeias do Jamari and Nova Esperança, respectively $(\mathrm{P}<0.05)$. The greatest genetic distance between different environments was attributed to the location of Nova Esperança with a value of 0.087 (Table 6) and the smallest genetic distance was attributed to the location of Mato Grosso with an estimated value of 0.007 (Table 6).

Table 5. Pairwise population matrix of Nei's genetic distance for Anopheles darlingi mosquitoes collected in three localities in Porto Velho (RO) and Candeias do Jamari (RO).

\begin{tabular}{lcccc}
\hline Population & São João & Candeias do Jamari & Mato Grosso & Nova Esperança \\
\hline São João & 0.000 & & & \\
Candeias & 0.042 & 0.000 & 0.000 & 0.142 \\
Mato Grosso & 0.051 & 0.057 & 0.112 & 0.000 \\
Nova Esperança & 0.088 & 0.12 & \\
\hline
\end{tabular}

Table 6. $\mathrm{F}_{\text {st }}$ and Nei's genetic distance (GD) values between Anopheles darlingi samples collected in peri-domicile and extra-domicile environments, in three localities in Porto Velho (RO) and in Candeias do Jamari (RO).

\begin{tabular}{lcc}
\hline Intra-domicile x peri-domicile & $\mathrm{F}_{\mathrm{st}}(\mathrm{P}<0.05)$ & GD \\
\hline São João & 0.019 & 0.040 \\
Candeias do Jamari & 0.013 & 0.061 \\
Mato Grosso & 0.025 & 0.007 \\
Nova Esperança & 0.031 & 0.087 \\
\hline
\end{tabular}

\section{DISCUSSION}

Donnelly et al. (2002), reviewing the accumulated body of information on population structure of malaria vectors, concluded that there is evidence of a shallow population structure and a weak effect of distance on population differentiation. The reasons for these facts are, among others, the high population numbers and the high mobility of these insects, A. darlingi not being an exception. The same researchers pointed out some important attributes of the species of malaria vectors, including their adaptations to exploit different man-made environments and a good dispersal and colonizing ability (Donnelly et al., 2002).

The genetic variability demonstrated in this study is comparable to that observed in the majority of other studies of $A$. darlingi in South America: the values found by PinedoCancino et al. (2006) for $\mathrm{H}_{\mathrm{e}}$ ranged from 0.270 to 0.320 for populations near the city of Iquitos in Peru. González et al. (2007) found average values of 0.374 and 0.309 with RAPD and 
AFLP markers, respectively. Santos et al. (1999) found values ranging from 0.290 to 0.375 for populations of different states of Brazil. However, these values are low when compared with results obtained with codominant DNA markers such as microsatellites (Santos et al., 1999), and high when compared with values obtained with isozyme markers by Manguin et al. (1999). In Table 2 and Figure 1, we can observe that at the two sites close to the urban area of Porto Velho (Mato Grosso and Nova Esperança), the three measures of genetic diversity, $\mathrm{H}_{\mathrm{e}}$, Shannon's information index and \%PL, are smaller than in the other two, São João and Candeias do Jamari, which are both closer to the forest. A possible explanation for these findings is the existence of a malaria control program in Porto Velho, which includes the use of chemical insecticides when necessary. The populations of Nova Esperança and Mato Grosso must have been frequently exposed to these malaria control actions, which may be less efficient in São João and Candeias do Jamari, where mosquito breeding sites must be very common.

The Shannon diversity index, more frequently used in ecological studies than in population genetics, has good properties to evaluate genetic diversity within populations, according to Lewontin (1972). When calculated on the basis of gene frequencies of biallelic loci, the minimum value is 0 and the maximum is 1 . In the present study (see Table 3), the Shannon index values are in the range of $0.410-0.568$. The values are consistently higher in the extradomicile than in the peri-domicile. This fact is not easily explained, but we should recall that mosquitoes are exposed to insecticides in the peri-domicile, but not in the extra-domicile.

The results of AMOVA (Figure 2) showed, as expected, that most of the genetic variability found in these populations is due to differences between individuals within populations (93\%), while $7 \%$ is due to differences between populations. González et al. (2007) give estimates of within population variation of $92 \%$, using RAPD markers, and $77 \%$ with AFLP, in populations of $A$. darlingi in Colombia. It must be noted that the sampled populations are not only much more distant than ours, but they are separated by mountains. The estimates of $\mathrm{F}_{\text {st }}$ are rather small, but the values of pairwise population distance are not so small, particularly the distance between the population of Nova Esperança and the other ones.

When all data of the peri-domicile are considered together and compared with the data from the extra-domicile, the values of $\mathrm{F}_{\mathrm{st}}$ and genetic distance are greater than the ones between pairs of localities, probably because environmental differences have a more important influence on the genetic composition of populations than the mere geographic distance. This fact deserves further attention because, as mentioned in other studies, there is evidence of changes in Anopheles darlingi behavior, mainly in its endophily and biting activity.

\section{REFERENCES}

Charlwood JD (1996). Biological variation in Anopheles darlingi Root. Mem. Inst. Oswaldo Cruz 91: 391-398.

Charlwood JD and Hayes J (1978). Variações geográficas no ciclo de picada do Anopheles darlingi Root no Brasil. Acta Amazon. 8: 601-603.

Conn JE, Bollback JP, Onyabe DY, Tessa NR, et al. (2001). Isolation of polymorphic microsatellite markers from the malaria vector Anopheles darlingi. Mol. Ecol. Notes 1: 223-225.

Conn JE, Vineis JH, Bollback JP, Onyabe DY, et al. (2006). Population structure of the malaria vector Anopheles darlingi in a malaria-endemic region of eastern Amazonian Brazil. Am. J. Trop. Med. Hyg. 74: 798-806.

Consoli RAGB and Oliveira RL (1994). Principais Mosquitos de Importância Sanitária no Brasil. Fio Cruz, Rio de Janeiro. Donnelly MJ, Simard F and Lehmann T (2002). Evolutionary studies of malaria vectors. Trends Parasitol. 18: 75-80.

Excoffier L, Smouse PE and Quattro JM (1992). Analysis of molecular variance inferred from metric distances among DNA haplotypes: application to human mitochondrial DNA restriction data. Genetics 131: 479-491. 
Excoffier L, Laval G and Schneider S (2005). Arlequin (version 3.0): an integrated software package for population genetics data analysis. Evol. Bioinform. Online 1: 47-50.

Forattini OP (2002). Culicidologia Médica. Vol. 2: Identificação, Biologia e Epidemiologia. Ed. da Universidade de São Paulo, São Paulo.

Fundação Nacional de Saúde (FNS) (2010). Sistema de Informação de Vigilância Epidemiológica - Malária (SIVEP Malária), Secretaria de Vigilância em Saúde, Ministério da Saúde. Vigilância. Programa Nacional de Controle de Malária. Available at [http://www.fns.saude.gov.br/]. Accessed April 21, 2010.

Gama RA, Santos RL, Santos FD, Silva IM, et al. (2009). Periodicity of capture of the Anopheles darlingi Root (Diptera: Culicidae) in Porto Velho, Rondônia, Brazil. Neotrop. Entomol. 38: 677-682.

Gil LH, Tada MS, Katsuragawa TH, Ribolla PE, et al. (2007). Urban and suburban malaria in Rondônia (Brazilian Western Amazon). II. Perennial transmissions with high anopheline densities are associated with human environmental changes. Mem. Inst. Oswaldo Cruz 102: 271-276.

González R, Wilkerson R, Suarez MF, Garcia F, et al. (2007). A population genetics study of Anopheles darlingi (Diptera: Culicidae) from Colombia based on random amplified polymorphic DNA-polymerase chain reaction and amplified fragment length polymorphism markers. Mem. Inst. Oswaldo Cruz 102: 255-262.

Janssen P, Coopman R, Huys G, Swings J, et al. (1996). Evaluation of the DNA fingerprinting method AFLP as a new tool in bacterial taxonomy. Microbiology 142: 1881-1893.

Lewontin RC (1972). The apportionment of human diversity. Evol. Biol. 6: 381-398.

Lynch M and Milligan BG (1994). Analysis of population genetic structure with RAPD markers. Mol. Ecol. 3: 91-99.

Magris M, Rubio-Palis Y, Menares C and Villegas L (2007). Vector bionomics and malaria transmission in the Upper Orinoco River, Southern Venezuela. Mem. Inst. Oswaldo Cruz 102: 303-311.

Malafronte RS, Marrelli MT and Marinotti O (1999). Analysis of ITS2 DNA sequences from Brazilian Anopheles darlingi (Diptera: Culicidae). J. Med. Entomol. 36: 631-634.

Manguin S, Wilkerson RC, Conn JE, Rubio-Palis Y, et al. (1999). Population structure of the primary malaria vector in South America, Anopheles darlingi, using isozyme, random amplified polymorphic DNA, internal transcribed spacer 2, and morphologic markers. Am. J. Trop. Med. Hyg. 60: 364-376.

Mendes-dos-Santos JM, Lobo JA, Tadei WP and Contel EPB (1999). Intrapopulational genetic differentiation in Anopheles (N.) darlingi Root, 1926 (Diptera: Culicidae) in the Amazon region. Genet. Mol. Biol. 22: 325-331.

Ministério da Saúde (2009). Malária no Brasil. Ministério da Saúde, Brasília.

Mirabello L, Vineis JH, Yanoviak SP, Scarpassa VM, et al. (2008). Microsatellite data suggest significant population structure and differentiation within the malaria vector Anopheles darlingi in Central and South America. B.M.C. Ecol. 8: 3.

Orlocci L (1978). Multivariate analysis in vegetation research. 2nd edn. Dr. W. Junk Publishers, The Hague.

Peakall R and Smouse PE (2006). GENALEX 6: genetic analysis in Excel. Population genetic software for teaching and research. Mol. Ecol. Notes 6: 288-295.

Pinedo-Cancino V, Sheen P, Tarazona-Santos E, Oswald WE, et al. (2006). Limited diversity of Anopheles darlingi in the Peruvian Amazon region of Iquitos. Am. J. Trop. Med. Hyg. 75: 238-245.

Rosa-Freitas MG, Broomfield G, Priestman A, Milligan PJ, et al. (1992). Cuticular hydrocarbons, isoenzymes and behavior of three populations of Anopheles darlingi from Brazil. J. Am. Mosq. Control Assoc. 8: 357-366.

Rozendaal JA (1990). Observations on the distribution of anophelines in Suriname with particular reference to the malaria vector Anopheles darlingi. Mem. Inst. Oswaldo Cruz 85: 221-234.

Santos JMM, Lobo JA, Tadei WP and Contel EPB (1999). Intrapopulational genetic differentiation in Anopheles (N.) darlingi Root, 1926 (Diptera: Culicidae) in the Amazon region. Genet. Mol. Biol. 22: 325-331.

Scarpassa VM and Conn JE (2007). Population genetic structure of the major malaria vector Anopheles darlingi (Diptera: Culicidae) from the Brazilian Amazon, using microsatellite markers. Mem. Inst. Oswaldo Cruz 102: 319-327.

Vos P, Hogers R, Bleeker M, Reijans M, et al. (1995). AFLP: a new technique for DNA fingerprinting. Nucleic Acids Res. 23: 4407-4414.

Yeh FC, Yang RC and Boyle T (1999). POPGENE, Version 1.31. Microsoft Window-Based Freeware for Population Genetic Analysis. Quick User Guide. University of Alberta, Alberta. 